\title{
A Review on Adsorption of Cationic Dyes using Activated Carbon
}

\author{
Nikita Chrishel Corda ${ }^{1 *}$ and $M$. Srinivas Kini ${ }^{1}$ \\ ${ }^{1}$ Department of Chemical Engineering, Manipal Institute of Technology, Manipal, Manipal Academy \\ Of Higher Education, India.
}

\begin{abstract}
In this article efficiency of activated carbon as a potent adsorbent of cationic dyes has been reviewed. Non-biodegradable nature of pollutants and their removal in the present generation is a great challenge. Therefore, extensive study on adsorption of these classes of pollutants from water bodies is being carried out. Methylene blue (majorly) a dye seen in the effluent streams of textile, printing, paper industries along with some of the commonly used cationic dyes in process industries and their sorption on activated carbon are reviewed here. High cost of commercially activated carbon which is a limitation to its extensive use have paved way for study of adsorption by naturally obtained and extracted activated carbon from agricultural wastes and various other sources. The purpose of this review paper is to summarize the available information on the removal of cationic dyes using naturally extracted and commercially obtained activated carbon. Various parameters such as temperature, initial dye concentration, $\mathrm{pH}$, contact time, adsorbent dosage, particle size, stirring, agitation etc. were studied and the optimum parameters were determined based on the experimental outcomes. Equilibrium data was examined using Langmuir, Freundlich, Temkin and Dubinin-Radushkevich and few other isotherm models. Kinetic studies also have been carried out to find the most suitable way of expressing the adsorption process.
\end{abstract}

Keywords: Adsorption, Cationic, Langmuir, Isotherm, Activated carbon.

\section{Introduction}

Urbanization has been taking place rapidly in recent years which has resulted in increase of all forms of pollution one of which is water pollution. Exhaust and waste water streams being let out from industries carry huge amount of various toxic substances. Dyes are one of the main pollutants of textile industries. They are composed of two main components: chromophone one which imparts color and the other is auxophone this not only behaves as a supplement to the former component but also gives the water-soluble property to the dye and enhances the affinity of the dye to the cloth material. There are different classes of dye depending upon various factors. One of the classification of dyes is based on the charge the molecule carries. Some of the dyes are cationic in nature (e.g., methylene blue) and some are anionic in nature (e.g., methyl orange). Dyes present in effluent streams that are emptied in water bodies can have adverse effects on human and marine life.

\footnotetext{
* Corresponding author: nikkicorda24@gmail.com
} 
Presence of methylene blue reduces the diffusion of light and thereby photosynthesis [1]. Concentration of dyes higher than $1 \mathrm{mg} / \mathrm{l}$ in water streams make it unfit for consumption and therefore quality testing and treatment of water becomes important [2]. But overall there are about 100,000 commercial dyes which are produced and account for massive amounts ranging from $7 \times 10^{5}-1 \times 10^{6}$ tons annually of which $65-70 \%$ of dyes are azo dyes [3]. Its low biodegradability [1] makes it a challenging task to eliminate it from water bodies. There are various methods that are used to treat dye contaminated water, some of them are osmosis, reverse osmosis, filtration, membrane filtration etc. In any process certain factors are to be taken to consideration such as economic feasibility, time required, availability of materials, design of the process. Adsorption is one of the recent methods that has gained attention for treatment of waste water streams as it is efficient compared to other existing methods. A good adsorbent is one that is highly porous and has a large surface area. Depending on the availability, its properties and ease of usage, activated carbon can be classified as a good adsorbent. Activated carbon can be produced or extracted by various waste materials such as organic wastes (coconut husk, rice husk, pomegranate peels, olive stones, apricot stones etc.) Activated carbon is known for its high adsorptivity.

Researches have been conducted to study the effect of activated carbon on adsorption of various dyes depending upon the source from which activated carbon is obtained. Some research have been carried out by using activated carbon from olive stones [4], tea waste [2], sugarcane bagasse, apricot stones [5], date stones [6], banana peel [7], tamarind seeds [7], orange peels [6], etc. For studies on adsorption and its efficiency there are some basic requirements: rate of adsorption and equilibrium data [1]. Parameters such as concentration of adsorbent, $\mathrm{pH}$, agitation temperature at which experiments are carried out can be varied to study the effect of adsorption on dyes [1].

\subsection{Cationic dyes}

As mentioned in the introduction dyes can be classified as cationic and anionic in nature depending upon the charge they carry. Cationic dyes possess a positive charge on its molecule and are also called as basic dyes. They are usually found along with a $\mathrm{ZnCl}_{2}$ or $\mathrm{HCl}$ complexes [2] Some of these dyes on which extensive studies have been carried out are methylene blue, malachite green [8], rhodamine 6G[9] basic yellow[10]. All these dyes are known to be toxic, capable of causing mutation, carcinogenic in nature. These dyes are capable of imparting color to water and are soluble with it [6]. Prolonged exposure to methylene blue can cause eye irritation [6], tachycardia [2], nausea, vomiting, slower the mental growth or retardation. Malachite green a cationic dye widely used in clothing industries, fish industries and at a large scale used as disinfectants in medical sector [8]. This pollutant too is known for having carcinogenic properties and cause mutation. Rhodamine 6G a dye which gives a dark reddish-brown appearance is from the rhodamine family known for stunting the growth in plants due to its adherence to lipid and phosphate molecules present in the cell membrane of plants. 


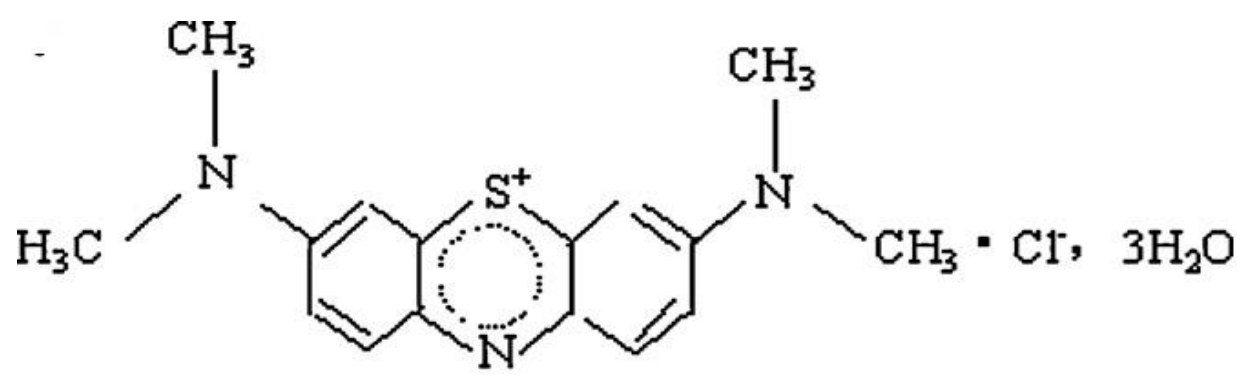

Methylene Blue

Fig. 1. Methylene Blue structure [11]

\subsection{Different methods of dye removal}

Few of the common techniques used for treatment of waste water streams polluted by dye are discussed below:

\subsubsection{Filtration}

There are different types of filtration process such as ultra-filtration, micro filtration, reverse osmosis, nano-filtration etc. Each of them are used for different purposes. Nano and ultrafiltration are the two types of processes that are generally used for treatment of waste water stream for removal of dyes. Drawback of this method is clogging of the pores which makes it an inefficient process. [3]

\subsubsection{Chemical treatment}

In this method coagulating and flocculating agents are used for dye removal. Ions such as Aluminium $\left(\mathrm{Al}^{3+}\right)$, Calcium $\left(\mathrm{Ca}^{2+}\right)$ etc. induces flocculation. Though the process is very feasible, the disadvantage of this method is the production of concentrated sludge due to which disposal becomes a problem. [3]

\subsubsection{Oxidation process}

Oxidizing agent are used in treatment of effluent streams. Chemical oxidation and UV assisted oxidation are the two common types in this process. These use low quantities of agent and short time for reaction. But the drawback of this process is formation of sludge [3], and $\left(\mathrm{H}_{2} \mathrm{O}_{2}\right)$ agent need activation for efficient performance [2].

\subsubsection{Adsorption using activated carbon}

Of the various methods explained and enlisted above adsorption is one of the most commonly used methods for removal of cationic dyes from industrial effluents. In this process the adsorbate or dye molecules adhere to surface of adsorbent. Adsorption is widely applicable for removal of wide range of dyes. The disadvantage of adsorption is the cost of adsorbent which makes it economically infeasible. In this paper we are reviewing different sources of agricultural waste from which activated carbon is prepared and can be used as adsorbent. By this method the process can be made economical. 
Table 1. Studies on adsorption of cationic dyes using activated carbon from different sources

\begin{tabular}{|l|c|c|}
\hline \multicolumn{1}{|c|}{ Adsorbents } & Dye & Source \\
\hline F400 commercial activated carbon & Methylene blue & {$[12]$} \\
\hline Pinewood (AC) & Methylene blue & {$[2]$} \\
\hline Activated carbon from textile sludge & MB & {$[13]$} \\
\hline CAC & MG & {$[8]$} \\
\hline Rice husk activated carbon & MG & {$[2]$} \\
\hline Carbon from jute fibers & MG & {$[8]$} \\
\hline Acorn AC & MB & {$[1]$} \\
\hline Oil palm wood AC & MB & {$[1]$} \\
\hline A C peanut shell & MG & {$[3]$} \\
\hline A C from pinedust & MG & {$[3]$} \\
\hline A C plum kernel & Basic red 22 & {$[3]$} \\
\hline A C bagasse & Basic red 22 & {$[6]$} \\
\hline A C corncob & MB & {$[6]$} \\
\hline A C rice husk & MB & {$[6]$} \\
\hline A C date stones & MB & {$[6]$} \\
\hline A C orange peels & MB & \\
\hline
\end{tabular}

\subsection{Activated carbon}

Activated carbon (AC), as the name suggests, is conventionally prepared from carbon from its various physical forms such as coal, coconut shell, wood etc., using physical or chemical activation methods and for all its virtues is the oldest known adsorbent to mankind. Physical and chemical activations [14], as discussed below, have their own merits and drawbacks. On one hand physical activation is more dependent or inclined towards use of elevated temperature and prolonged activation time and on the other hand chemical activation needs a rigorous and exhaustive cleaning of substrate because of exposure to chemical reagents [12].

\subsubsection{Physical activation:}

Initially, the substrate or source material is subjected to hot gases to be further developed into activated carbon. After the hot air treatment, the source material is then required to be burnt out of gases, giving way to a graded, concealed and dustless form of activated carbon. To achieve such an outcome from a relatively complicated process, a combination of techniques is used that are discussed below:

- Carbonization: It is the term for the conversion of an organic substance into carbon or a carbon-containing residue through destructive distillation, commonly known as pyrolysis, at $600-900{ }^{\circ} \mathrm{C}$, conventionally with inert gases such as argon or nitrogen.

- Activation/Oxidation: Material obtained from carbonization is subjected to oxidization (oxygen or steam) with temperatures ranging well above $300^{\circ} \mathrm{C}$, is in the vicinity of 600 $900^{\circ} \mathrm{C}$ 
1.3.2 Chemical activation: It acts as a precursor to carbonization. Here, the raw material is typically injected with an acid, base or salt. After this process, the previous step of carbonization is repeated but this time at a slightly lower temperature range of $400-900^{\circ} \mathrm{C}$. The raw material is then carbonized at lower temperatures $\left(450-900{ }^{\circ} \mathrm{C}\right)$. Although there is no certain proof for it but scientists widely agree that the activation step proceeds parallel to chemical activation.

Activated charcoal has been used for over 100 years for the treatment of toxic ingestions, and continues to be the most common form of gastrointestinal decontamination for the poisoned patient [15]. Though commercially available activated carbon (CAC) are usually derived from natural materials such as biomass, lignite or coal, but almost any carbonaceous materials may be used as precursor for the preparation of carbon adsorbents because of its commercial availability and cheapness, coal is the most widely used precursor to produced activated charcoal $[10,16]$.

\subsubsection{Properties [17]}

1 gram of activated carbon has surface area ranging from $500 \mathrm{~m}^{2}$ to $1500 \mathrm{~m}^{2}$ which is available commercially. Carbon aerogels, which have higher surface areas are expensive, and are used in specific applications. Electron microscope, reveal the structure of high surface area of activated carbon. Particles that are extremely complicated exhibit innumerable kinds of porosity; but there can be regions where flat planes of graphite-like material run parallel to each other, which may be disconnected by few nanometers. These micro-pores provide excellent conditions for adsorption such that adsorbing material can interact with various surfaces concurrently. Testing of adsorption behavior are generally carried out with nitrogen gas at $7 \mathrm{~K}$ under high vacuum condition. On a general basis activated carbon is perfectly capable of producing its equivalent, by adsorption from its environment, liquid water from steam at $100^{\circ} \mathrm{C}\left(212^{\circ} \mathrm{F}\right)$ and a pressure of $1 / 10,000$ of an atmosphere.

\subsubsection{Applications of activated carbon}

The unique properties of activated carbon find its way to following applications:

1. Water purification

2. Gas purification

3. Gold and precious metal recovery

4. Pharmaceuticals and drug industry

5. Thermal and nuclear power stations

6. Waste water treatment

7. Petroleum

Coal is a mixture of carbonaceous materials, formed by the degradation of plants and formation of fossils over ages. The adsorption properties of each coal are determined by the manner by which the plants cultivated and the extent of the physical-chemical changes occurring after deposition. Coal adsorption capacities are given below. 
Table 2. Adsorption capacities of commercially activated carbon for MB [18-20]

\begin{tabular}{|c|c|}
\hline Adsorbents & Adsorption capacity (mg/g) \\
\hline Commercial activated carbon & 980.3 \\
\hline Activated carbon produced from New Zealand coal & 588 \\
\hline Filtrasorb 400 & 476 \\
\hline Activated carbon & 400 \\
\hline Activated carbon produced from Venezuelan & 380 \\
\hline bituminous coal & 324 \\
\hline Peat & 323.68 \\
\hline Coal & 299 \\
\hline Filtrsorb 400 & 276 \\
\hline Norit & 246 \\
\hline Picacarb & 240 \\
\hline Filtrasorb 300 & 230 \\
\hline Coal & 200 \\
\hline Commercial activated carbon & 176 \\
\hline Bituminous Coal & 62.7 \\
\hline Charcoal & \\
\hline & \\
\hline & \\
\hline & \\
\hline & \\
\hline & \\
\hline
\end{tabular}

\subsubsection{Classification}

Depending upon size of particle, methods of preparation and industrial applications activated carbon can be classified as follows:

\section{Powdered activated carbon (R1, PAC)}

Activated carbon is generally prepared in particulate form as fine granules which have a size of $1 \mathrm{~mm}$ having an average diameter ranging from 0.15 to $0.25 \mathrm{~mm}$. With this structure achieving higher surface to volume ratio and small diffusion distance becomes easier. Activated carbon (R1) are those particles of activated carbon which retain on a 50-mesh sieve $(0.297 \mathrm{~mm})$.

\section{Granular activated carbon (GAC)}

Granular activated carbon, these comparatively have larger particle size than powdered activated carbon and hence represent a smaller external surface. GAC are classified depending on their dimensions where particles having sizes $8 \times 20,20 \times 40$, or $8 \times 30$ are used for liquid phase applications and $4 \times 6,4 \times 8$ or $4 \times 10$ are used for vapor phase applications.

\section{Bead activated carbon (BAC)}

Petroleum pitch is used for the production of bead activated carbon and are available in diameter ranging between $0.35 \mathrm{~mm}$ to $0.8 \mathrm{~mm}$. It is also known for its low $\Delta \mathrm{P}$, high mechanical strength and low dust content, with a smaller pellet size. It is widely used in fluidized bed applications such as water filtration which could be credited to its spherical structure. 


\section{Effect of parameters}

\subsection{Effect of temperature}

Temperature is an important parameter in adsorption studies. For any process it is essential to know to what extent does temperature bear an effect on the efficiency of adsorbent. Experiments are conducted at different temperatures ranging from $293 \mathrm{~K}-333 \mathrm{~K}$ by keeping all other parameters constant [1]. The nature of the process can be understood depending upon the way process reacts with variation in applied temperature. A process or a reaction is said to be endothermic in nature if the sorption of dye on the adsorbent sees a rise due to increase in temperature and exothermic if there is a fall in the adsorption capacity with increase in temperature. Adsorption of methylene blue dye on commercially activated carbon is an endothermic process. Two main effects of temperature on this process are increase in the rate of diffusion of the dye molecules on the outer surface of $\mathrm{AC}$ and the other increased movement of molecules thereby leading to reduced viscosity [1]. The same was seen in adsorption of MB using olive stone and olive stone activated carbon (OSAC) [4]. Increasing the temperature beyond a certain limit to achieve better adsorptivity is also not advisable since it has an effect on the operating cost [5]. It is seen that for most of the adsorbent used for uptake of MB (whatever the source of activated carbon used) had an endothermic natured process $[11,2,21-23]$.

\subsection{Effect of contact time}

Contact time refers to the amount of time the adsorbent is in contact with the dye solution. Amount of MB that was adsorbed onto OSAC increased with the rise in contact while keeping the other parameters constant [4]. For a dye solution of $50 \mathrm{mg} / \mathrm{l}$ a contact time of $15 \mathrm{~min}$ was sufficient whereas for a dye of about $120 \mathrm{mg} / 1$ concentration the time to attain equilibrium was about 30 minutes [4]. With increase in dye concentration the contact time required to reach equilibrium gets higher. The adsorption of $\mathrm{MG}$ was rapid till $120 \mathrm{~min}$ of contact and thereafter plateau is observed until equilibrium. And no further dye could be adsorbed [8]. The uptake of MG-5 increased continuously until 30 min of contact time after which removal rate decreased slightly and plateaued after $120 \mathrm{~min}$. The quick adsorption from 50.1 to $72.8 \%$ within 1 min suggests strong affinity for the cationic dye molecule [24].The same trend was followed when C-PAN (Persean Americana nuts)was introduced in basic yellow 28 dye solution where during the first 15 min the adsorbing capacity was high followed by low adsorption rate until equilibrium was established at $30 \mathrm{~min}$. depending upon the type of adsorbent being used and the removal \% expected from the adsorbent the optimal contact time can range from few min to few hours[25].

\subsection{Effect of $\mathrm{pH}$}

$\mathrm{pH}$ refers to the acidity or basicity of a solution. Solution having $\mathrm{pH}$ value below 7 are termed as acids/acidic in nature and $\mathrm{pH}$ above 7 are alkaline in nature where neutrality is at $\mathrm{pH} 7$. $\mathrm{pH}$ gives an account of degree of ionization of acidic or basic compounds in adsorption process [1]. $\mathrm{pH}$ values are generally altered by using $\mathrm{NaOH}$ and $\mathrm{HCl}$ [5]. $\mathrm{pH}$ value can alter the surface charge of $\mathrm{A} \mathrm{C}$ and functional group of the dye [23]. In the experiment of $\mathrm{MB}$ uptake using olive stone $\mathrm{AC}$ it was seen that there was increase in the amount adsorbed from $6.4-8.3 \mathrm{mg} / \mathrm{g}$ but optimum value was found at $\mathrm{pH} 5$ having $9.5 \mathrm{mg} / \mathrm{g}$ uptake. There is no significant change in the adsorption capacity of adsorbent with variation in $\mathrm{pH}$ [22]. The 
same is in accordance with adsorption of MB dye using CAC by varying $\mathrm{pH}$ between 2-11[1], but there was a significant change in the surface charge the drop in the $\mathrm{pH}$ value shows reduced hydrolysis of the groups, simultaneous increase in the stability of $(\mathrm{MB})^{+}$was seen. In adsorption process of MB using ASAC there was an evident rise in the efficiency of adsorption with increase of $\mathrm{pH}$ credited to the protonation dye in the acidic medium and presence of excess $\mathrm{H}^{+}$ions showing optimum value at $\mathrm{pH} 5$ [5]. Whereas in adsorption of MG using $\mathrm{CO}_{2}$ activated carbon it was seen that max adsorption (35.5\%-93.2\%) took place at $\mathrm{pH}$ 2-8 but further increase from 8-12 showed no such effect and was almost negligible impact due to the increased negative charges on $\mathrm{CO}_{2}$ activated carbon surface at this $\mathrm{pH}$ [8].

\subsection{Effect of initial dye concentration}

Initial dye concentration studies and its effects on adsorption can be understood by treating different concentration dye with adsorbent dose maintained constant. For experiment of AC treatment of $\mathrm{MB}$ dye by varying the initial dye concentration, it was seen that achieving equilibrium with lower concentration of dye was much easier compared to higher concentration levels. It is to be mentioned that the rate at which dye is adsorbed is faster at high concentration initially and then steadily attains equilibrium [1]. The same was seen in textile sludge activated carbon used as adsorbent also indicating the faster rate is due to high driving force initially which gradually reduces [13]. In most of the cases it's seen that the initial dye concentration and removal $\%$ are inversely related to each other as active sites are saturated in the presence of higher initial concentration [2].

Table 3. Adsorption capacity on varying initial dye concentration

\begin{tabular}{|l|c|c|c|c|c|}
\hline Adsorbents & Dye & $\begin{array}{c}\text { Initial dye } \\
\text { concentration } \\
(\mathrm{mg} / \mathrm{l})\end{array}$ & $\%$ removal & $\begin{array}{c}\text { Adsorption } \\
\text { Capacity } \\
(\mathrm{mg} / \mathrm{g})\end{array}$ & References \\
\hline Sawdust Carbon & $\mathrm{MB}$ & $50-250$ & $99 \%-82.2 \%$ & $12.49-51.4$ & {$[2]$} \\
\hline $\begin{array}{l}\text { Apricot Stone AC } \\
\text { (ASAC) }\end{array}$ & $\mathrm{MB}$ & $5-100$ & $99 \%-67 \%$ & ---- & {$[5]$} \\
\hline Olive Stones AC & MB & $50-150$ & ------ & $4.8-12.4$ & {$[4]$} \\
\hline $\begin{array}{l}\text { Ficus Carica Bast } \\
\text { AC (FCBAC) }\end{array}$ & MB & $40-90$ & $80-50$ & $30-45$ & {$[26]$} \\
\hline Coconut shell AC & MB & $10-50$ & $87.8-39.6$ & -- & {$[21]$} \\
\hline
\end{tabular}

\subsection{Effect of adsorbent dosage and particle size}

Optimal amount of adsorbent to be used for adsorption can be studied extensively by carrying out experiments where the adsorbent dosage is varied when other conditions are maintained constants. In an experiment of removal of MB dye using CAC it was seen that a dosage of $0.1 \mathrm{~g}$ was sufficient to get maximum removal \% where initial dye concentration was $10 \mathrm{mg} / \mathrm{l}$ with agitation speed of $200 \mathrm{rpm}$ at $298 \mathrm{~K}$ were maintained [5]. This was in correspondence with removal of MB using FCBAC when the adsorbent dosage was varied from $0.1 / 100 \mathrm{ml}$ to $0.5 / 100 \mathrm{ml}$ [26]. Same was seen that with an increase in dosage from $2-12 \mathrm{~g} / 1$ the removal $\%$ varied from $35-90 \%$ for $\mathrm{CP} 13$ [27]. Generally, it is seen that with rise in the adsorbent dosage the removal \% or its efficiency gets better as the number of vacant sites available for uptake of dye are more [2]. But to achieve better adsorption we cannot keep increasing the 
adsorbent dose as cost becomes a limiting factor and therefore finding an optimal dosage for any process of dye adsorption has to be considered.

The CAC used for removal of MB dye had the following physical parameters [1]

Table 4. Physical properties of commercially activated carbon

\begin{tabular}{|l|c|}
\hline BET surface area $\left(\mathrm{m}^{2}\right)$ & 900 \\
\hline Particle size $(\mu \mathrm{m})$ & 150 \\
\hline Mesopore vol. $\left(\mathrm{cm}^{3} / \mathrm{g}\right)$ & 0.058 \\
\hline Micropore vol. $\left(\mathrm{cm}^{3} / \mathrm{g}\right)$ & 0.294 \\
\hline
\end{tabular}

It is seen in an adsorption process study of MB uptake using PAC2 the adsorption capacity of the adsorbent did rise with smaller particle size of PAC2. The solution of $600 \mathrm{mg} / \mathrm{dm}^{3}$ showed an increase in adsorption from $253-325 \mathrm{mg} / \mathrm{g}$ as the particle size of adsorbent was varied between $106-180 \mu \mathrm{m}$ when compared to particle size which was maintained below $106 \mu \mathrm{m}[10]$.

\subsection{Effect of stirring /agitation speed}

Adsorption of MB using CAC as adsorbent was studied at different mixing rates experiments were carried out at $293 \mathrm{~K}$ by varying stirring speed from $90-150 \mathrm{rpm}$ for a solution of $120 \mathrm{mg} / \mathrm{l}$ concentration. From the experiment, it was concluded that this parameter did not have any significant effect on removal \% of dye [1]. Depending upon the agitation speed of a solution it can be understood that the rate controlling step could either be film diffusion or pore diffusion. On agitating MB solution between 50-300rpm with initial dye concentration of $10 \mathrm{mg} / \mathrm{l}$ adding $0.01 \mathrm{~g}$ of adsorbent at $298 \mathrm{~K}$ following were concluded [5].

Table 5. Optimum stirring speed for MB adsorption

\begin{tabular}{|c|c|c|}
\hline Adsorbent & $\begin{array}{c}\text { Optimum Stirring speed } \\
(\mathrm{rpm})\end{array}$ & Efficiency/ removal \% \\
\hline CAC & 200 & 97.4 \\
\hline ASAC & 100 & 99.2 \\
\hline
\end{tabular}

\section{Adsorption isotherms}

There are different types of adsorption isotherms such as: Freundlich, Langmuir, and Temkin, Harkins-jura, R-D isotherms among which the former two are widely used. Depending on the type of data available any of them could be used for best fitting of the data. Adsorption isotherm in general refers to a graphical representation giving a relation between amount of adsorbate adsorbed on to surface of an adsorbent. There are basically two types of isotherm depending on the parameters

1. Two parameter isotherms: Langmuir, Freundlich, Temkin, R-D isotherms, hill isotherms.

2. Three parameter isotherms: this include Redlich-Peterson, sips model, khan isotherm, Radke-Prausnitz isotherm [28]. 


\subsection{Two Parameter Models [4]}

\subsubsection{Langmuir isotherm}

Langmuir isotherm assumes that a single layer of adsorption takes place on the surface of adsorbent having certain number of vacant sites for adsorption of uniform strategies of adsorption. The expression for Langmuir isotherm is given as follows

$$
\frac{C_{e}}{q_{e}}=\frac{1}{Q_{o} K_{L}}+\frac{C_{e}}{Q_{o}}
$$

Where $\mathrm{C}_{\mathrm{e}}$ refers to concentration of adsorbate at equilibrium.

$\mathrm{q}_{\mathrm{e}}$ refers to adsorbate that has been adsorbed /unit mass of adsorbent

$\mathrm{Q}_{\mathrm{O}}, \mathrm{K}_{\mathrm{L}}$ are the adsorptivity rate constant of adsorption process

A dimensionless parameter $\mathrm{R}_{\mathrm{L}}$ gives the essential characteristics of Langmuir isotherm and can be given as

$$
\mathrm{R}_{\mathrm{L}}=\frac{1}{1+K_{L} C_{e}}
$$

\subsubsection{Freundlich isotherm}

In this isotherm heterogeneous/non-homogenous surface with a non-uniform distribution of heat of sorption over surface is assumed. This is given by

$$
\log \mathrm{q}_{\mathrm{e}}=\log \mathrm{K}_{\mathrm{F}}+\frac{1}{n} \log \mathrm{C}_{\mathrm{e}}
$$

$\mathrm{K}_{\mathrm{F}}, \mathrm{n}$ are Freundlich isotherm constants where $\mathrm{n}$ values generally range from 1-10. Increased value of $\mathrm{n}$ shows better adsorption

\subsubsection{Temkin isotherm}

Here it is assumed that heat of adsorption of all molecules in the layer reduces linearly with coverage. This is due to the interactions that exist between the dye and activated carbon molecules in this case. It is given by:

$$
\mathrm{q}_{\mathrm{e}}=\mathrm{B}_{\mathrm{T}} \ln \mathrm{K}_{\mathrm{T}}+\mathrm{B}_{\mathrm{T}} \ln \mathrm{C}_{\mathrm{e}}
$$

$\mathrm{K}_{\mathrm{T}}$ is equilibrium binding constant,

$$
\mathrm{B}_{\mathrm{T}}=\mathrm{RT} / \mathrm{b}
$$

$\mathrm{R}$ is the gas constant, $\mathrm{T}$ absolute temperature.

3.1.4 Dubinin-Radushkevic: The model is given as follows:

$$
\ln \mathrm{q}_{\mathrm{e}}=\ln \mathrm{Q}_{\mathrm{s}}-\mathrm{B} \dot{\varepsilon}^{2}
$$

Where $\dot{\varepsilon}$ is known as Polanyi potential

$$
\dot{\varepsilon}=\mathrm{RT} \ln \left(1+\frac{1}{C_{e}}\right)
$$


The relation between mean energy for sorption and $\mathrm{B}$ is given as

$$
\mathrm{E}=\frac{1}{\sqrt{2 B}}
$$

The E value gives relation of physical and chemical nature of adsorption

\subsubsection{The Harkins-Jura isotherm [4]}

$$
\frac{1}{q e^{2}}=\frac{B_{2}}{A}-\frac{1}{A} \log C_{e}
$$

Where $\mathrm{q}_{\mathrm{e}}$-adsorption at equilibrium and $\mathrm{C}_{\mathrm{e}}$ is the concentration at equilibrium

$\mathrm{A}$ is Harkins-Jura isotherm parameter and $\mathrm{B}_{2}$ is the isotherm constant.

In this isotherm it is assumed that multilayer adsorption takes place in an heterogenous pore distribution.

\subsection{Three Parameter Models [28]}

\subsubsection{Redlich-Peterson isotherm}

$$
q_{e}=\frac{K_{R} C_{e}}{1+a_{R} C_{e}^{g}}
$$

A combination of both Langmuir and Freundlich isotherms, which three parameter isotherm. The isotherm is linearly dependent on concentration in the numerator and an exponential function in the denominator to represent adsorption equilibria. This could be done over a wide concentration range in both homogeneous or heterogeneous systems due to its versatility.

\subsubsection{Sips isotherm}

Just like Redlich-Peterson isotherm this also is a combination of both Langmuir and Freundlich isotherm which is generally applicable to heterogeneous adsorption systems. This isotherm is influenced by the working conditions of the adsorption process such as $\mathrm{pH}$, temperature and concentrations.

$$
q_{e}=\frac{K_{s} C_{e}^{\beta s}}{1+C_{e}^{\beta s} a_{s}}
$$

Following is a table of various adsorbent and adsorbate combination and their relation with adsorption isotherms. 
Table 6. Adsorption isotherms for dyes using different adsorbents

\begin{tabular}{|c|c|c|c|c|}
\hline Adsorbent & Dye/adsorbate & Isotherm & Constants & Source \\
\hline CAC & MB & Langmuir & $\begin{array}{c}\mathrm{q}_{\mathrm{m}}=146.46 ; \mathrm{K}=1.11 \\
\mathrm{R}^{2}=0.998(293 \mathrm{~K})\end{array}$ & [1] \\
\hline $\begin{array}{l}\text { Olive stone } \\
\text { activated } \\
\text { carbon }\end{array}$ & MB & Temkin & $\mathrm{R}^{2}=0.997$ & [4] \\
\hline Olive stone & MB & Temkin & $\mathrm{R}^{2}=0.995$ & [4] \\
\hline $\begin{array}{l}\text { Textile sludge } \\
\text { AC }\end{array}$ & MB & Freundlich & $\mathrm{K}_{\mathrm{F}}=0.165 ; \mathrm{n}=1.280$ & [13] \\
\hline $\begin{array}{l}\text { Apricot stones } \\
\text { AC }\end{array}$ & MB & Langmuir & $\begin{array}{c}\mathrm{q}_{\mathrm{m}}=36.68 ; \mathrm{K}_{\mathrm{L}}=23.3 \\
; \mathrm{R}^{2}=0.961\end{array}$ & {$[5]$} \\
\hline CAC & MB & Langmuir & $\begin{array}{c}\mathrm{q}_{\mathrm{m}}=199.60 ; \\
\mathrm{K}_{\mathrm{L}}=2.97 ; \mathrm{R}^{2}=0.964\end{array}$ & {$[5]$} \\
\hline Pinewood AC & MB & Langmuir & $\mathrm{q}_{\mathrm{m}}=5.56$ & {$[2]$} \\
\hline $\begin{array}{l}\text { AC from } \\
\text { pinedust }\end{array}$ & $\mathrm{MG}$ & Langmuir & $\mathrm{q}_{\mathrm{m}}=370.37$ & {$[3]$} \\
\hline $\begin{array}{l}\text { A C peanut } \\
\text { shell }\end{array}$ & $\mathrm{MG}$ & Langmuir & $\mathrm{q}_{\mathrm{m}}=222.22$ & {$[3]$} \\
\hline $\begin{array}{l}\text { Mesoporous A } \\
\text { C }\end{array}$ & MB & Langmuir & $\begin{array}{c}\mathrm{q}_{\mathrm{m}}=336.3, \mathrm{~K}_{\mathrm{L}}=1.004 ; \\
\mathrm{T}=293 \mathrm{~K}\end{array}$ & [23] \\
\hline $\mathrm{AC}$ rice husk & MB & Freundlich & $\begin{array}{c}\mathrm{T}=303 \mathrm{~K} ; \\
\mathrm{q}_{\mathrm{L}}=9.8 \mathrm{mg} / \mathrm{g}\end{array}$ & [6] \\
\hline $\begin{array}{l}\text { AC } \\
\text { sunflowerhulls }\end{array}$ & MB & Langmuir & $\begin{array}{c}\mathrm{T}=303 \mathrm{~K} ; \\
\mathrm{q}_{\mathrm{L}}=473.4 \mathrm{mg} / \mathrm{g}\end{array}$ & {$[6]$} \\
\hline $\begin{array}{l}\text { AC walnut } \\
\text { shells }\end{array}$ & MB & Redlich-Peterson & $\begin{array}{c}\mathrm{T}=298 \mathrm{~K} ; \\
\mathrm{q}_{\mathrm{L}}=355.5 \mathrm{mg} / \mathrm{g}\end{array}$ & {$[6]$} \\
\hline $\begin{array}{l}\text { AC Date } \\
\text { stones }\end{array}$ & MB & Sips & $\begin{array}{c}\mathrm{T}=303 \mathrm{~K} \\
; \mathrm{q}_{\mathrm{L}}=369.4 \mathrm{mg} / \mathrm{g}\end{array}$ & [6] \\
\hline
\end{tabular}

\section{Adsorption kinetics}

The rate of adsorption is given by adsorption kinetics in terms of order of the rate constant [2]. This adsorption rate is essential to decide the type or the best suited adsorbent for a specific process and this is governed by two main properties of adsorbent. One is the adsorption capacity and the other is the rate of adsorption. Most of the adsorption kinetics fall under one of the two types:

1. Pseudo- first order

2. Pseudo-second order

The adsorption process is then evaluated and is checked for the best kinetics that is applicable.

\subsection{Pseudo- first order (PFO)}

The adsorption rate for this kinetics is given by Lagergren; [4] 


$$
\ln \left(\mathrm{q}_{\mathrm{e}}-\mathrm{q}\right)=\ln \mathrm{q}_{\mathrm{e}}-\mathrm{k}_{1} \mathrm{t}
$$

where $\mathrm{q}_{\mathrm{e}}$ refers to the dye adsorbed $(\mathrm{mg} / \mathrm{g}$ ) at equilibrium and $\mathrm{q}$ is the amount of dye adsorbed at any time $\mathrm{t}$

$\mathrm{k}_{1}$ is the rate constant for pseudo first order kinetics $\left(\mathrm{min}^{-1}\right)$

when the adsorption is characterized by diffusion through a boundary the following equation applies when $\mathrm{n}=1[2]$.

$$
-r_{A}=C_{A}^{n}
$$

\subsection{Pseudo-second order model [2]}

$$
\frac{t}{q_{t}}=\frac{1}{K_{2} q_{e}^{2}}+\frac{t}{q_{e}}
$$

\subsection{Intraparticle diffusion model [4]}

The adsorption process has three steps: Film diffusion, Pore diffusion, intra-particle transport.

The slowest step among the three is called as the rate determining step. Intraparticle diffusion is given by

$$
\mathrm{q}_{\mathrm{t}}=\mathrm{k}_{\mathrm{diff}} \mathrm{t}^{0.5}+\mathrm{C}
$$

where $\mathrm{k}_{\text {diffi }}$ is the intraparticle diffusion rate constant $(\mathrm{mg} / \mathrm{g} \min )$ and $\mathrm{C}$ is the intercept $(\mathrm{mg} / \mathrm{l})$ indicating that the line does not pass through the origin which is attributed to the difference in the initial and final mass transfer rates. The intercept gives an idea about the thickness of the boundary layer higher the value of which greater is the thickness.

Where $\mathrm{q}_{\mathrm{t}}$ and $\mathrm{q}_{\mathrm{e}}$ are the amount of dye adsorbed at time $\mathrm{t}$ and at equilibrium respectively. $\mathrm{k}_{2}$ is the rate constant for pseudo second order kinetics $(\mathrm{g} / \mathrm{mg} \mathrm{min})$.

This model shows or follows a linear path. Depending upon the linear regression coefficient $\mathrm{R}^{2}$ the best model for process can be inferred.

Generally, for cationic dye adsorption pseudo second order represents the system better [2].

For adsorption of MB from macore fruit shells revealed that the $\mathrm{R}^{2}$ value was max for pseudo second order kinetics [22]. The same was seen in adsorption of the MB dye using OSAC and OS as adsorbent suggesting that overall rate was controlled by chemical adsorption. But in contrast the MB dye adsorption onto surface of ASAC should better results for intraparticle diffusion [2]. An experiment of malachite green adsorption using $\mathrm{CO}_{2}$ activated carbon gave the best result for intraparticle diffusion model [8].

\section{Regeneration of activated carbon}

Regeneration of the adsorbent is essential as excess amounts untreated can lead to problems in disposal. The adsorbent used can be reused for future applications. It is seen that regeneration of adsorbents from different agricultural sources show good amount of adsorption. The different methods of regeneration are biosorbents [25], carbonization of 
activated carbon, thermal regeneration [8]. It is seen that as we increase the regeneration cycles the adsorption capacity decreases.

Table 7. Adsorption capacity of adsorbents on regeneration

\begin{tabular}{|c|c|c|c|}
\hline Adsorbent & Dye & $\begin{array}{c}\text { Adsorption Capacity } \\
(\mathrm{mg} / \mathrm{g})\end{array}$ & References \\
\hline C-PAN & MB & $235-37.3$ & {$[25]$} \\
\hline A C from fuel oil & MB & $37-28$ & {$[9]$} \\
\hline A C from fuel oil & Rhodium 6G & $27-18$ & {$[9]$} \\
\hline CAC & MB & $210.18-148.51$ & {$[8]$} \\
\hline
\end{tabular}

\section{Conclusions}

Adsorption has been extensively studied and still research is being continued on efficient methods of dye removal.in this review paper various works have been compared and following are some of the findings

- Most of the agriculture based AC have good potential for adsorption of cationic dyes

- On uptake of MB dye varying pH over certain range and stirring did not show any significant changes.

- Initially for higher dye concentration the uptake of dye by the adsorbent is high and then slowly reaches equilibrium

- Depending upon the agitation and the process response towards it one can identify the rate limiting step between film and pore diffusion

- Adsorption isotherms of two and three parameter were used for studies and it was observed that most of them gave good results for Langmuir isotherms.

- Adsorption kinetics for the adsorption processes were not very satisfying for pseudofirst order kinetics when compared to the second order or intraparticle diffusion.

\section{References}

1. S.Karaca, A. Gurses, M.Acikyildiz, M.Ejder "Adsorption of cationic dye from aqueous solutions by activated carbon” Microporous Mesoporous Mater 115 376-382 (2008).

2. Mohammad Amran Mohd Salleh, Dalia Khalid Mahmood, Wanazlina wan abdul karim, Azniidris "Cationic and anionic dye adsorption by agricultural solid wastes: A comprehensive review" Desalination (2011).

3. V.K. Gupta, Suhas "Application of low cost adsorbents for dye removal-A Review" J. Environ. Manage.90 2313-2342 (2009).

4. RihamHazza, Mohammed Hussein "Adsorption of Cationic dye from aqueous solution onto activated carbon prepared from olive stones" Environmental Technology and Innovation 4 36-51 (2015).

5. Chahrazed Djilani, Rachida Zaghdoudi, Faycal Djazi, Bachir Bouchekima, Abdelaziz Lallam, Ali Modarressi, Marek Rogalski "Adsorption of dyes on activated carbon prepared from apricot stones and commercial activated carbon" J Taiwan Inst Chem Eng 53 112-121 (2015). 
6. J Muthanna Ahmed "Applications of agricultural based activated carbons by microwave and conventional activations for basic dye adsorption:Review" J Environ Chem Eng 4 89-99 (2016).

7. V.Tharaneedhar, P.Senthilkumar, A.Saravannan, C.Ravikumar, V.Jaikumar "Prediction and interpretation of adsorption paameters for the sequestration of methylene blue dye from aqueous solution using microwave assisted corncob activated carbon" SM\&T 11 1-11 (2017).

8. Miao $\mathrm{Yu}$, Yingyinghan, Jianli, Lijuan Wang “CO2-Activated porous carbon derived from cattail biomass for removal of malachite green dye and application as super capacitors" Chem. Eng. J 317 493-502 (2017).

9. Nabeel Jarrah "Competitive adsorption isotherms of rhodium 6G and methylene blue on activated carbon prepared from residual fuel oil" J Environ Chem Eng S2213-3437 30390-1 (2017).

10. N.Emad El Qada, J.Stephen Allen, M.Gavin Walker "Adsorption of basic dyes from aqueous solution onto activated carbons" Chem. Eng. J 135 174-184 (2008).

11. Wenhong Li, Qinyan Yue, Peng Tu, Zuohao Ma, Baoyu Gao, Jinze Li, Xing Xu "Adsorption characteristics of dyes in columns of activated carbon prepared from paper mill sewage sludge" Chem. Eng. J 178 197-203 (2011).

12. Mohd.Rafatullah, Othman Sulaiman, Rokiah Hashim, AneesAhmed "Adsorption of Methylene blue on low cost adsorbents: A Review" J. Hazard. Mater. 177 70-80 (2010).

13. Syieluing Wong, Nurul Atiqah Najlaa Yac'cob, Nozrita Ngadi, Onn Hassan, M.Ibrahim Inuwa "From Pollutant to solution of wastewater pollution: Synthesis of activated carbon from textile sludge for dyes adsorption" S1004-9541 (17) 30748-6

14. J. Romanos, M. Beckner, T. Rash, L. Firlej, B. Kuchta, P. Yu, G. Suppes, C. Wexler, P. Pfeifer. "Nanospace engineering of KOH activated carbon". Nanotechnology. 23 (1): 015401. doi:10.1088/0957-4484/23/1/015401 (2012).

15. American Academy of Clinical Toxicology Position Paper: "Single-Dose Activated Charcoal. Clin Toxic".

16. G.G. Stavropoulos, A.A. Zabaniotou, "Production and characterization of activated carbons from olive-seed waste residue", Microporous Mesoporous Mater

17. P.J. Paul "Value Added Products from Gasification - Activated Carbon". The Combustion, Gasification and Propulsion Laboratory (CGPL) at the Indian Institute of Science (IISc).

18. N. Kannan, M.M. Sundaram, "Kinetics and mechanism of removal of methylene blue by adsorption on various carbons - a comparative study", Dyes Pigm.

19. A.N. Fernandes, C.A.P. Almeida, C.T.B. Menezes, N.A. Debacher, M.M.D. Sierra, "Removal of methylene blue from aqueous solution by peat", J. Hazard. Mater.

20. K.V. Kumar, S. Sivanesan, "Equilibrium data, isotherm parameters and process design for partial and complete isotherm of methylene blue onto activated carbon", J. Hazard. Mater

21. A.Umar Isah, Giwa Abdulraheem, Salisu Bala, Sallahudeen Muhammed, "Kinetic, equilibrium and thermodynamics studies of C.J Reactive Blue 19 dye adsorption of coconut shell based activated carbon" Int Biodeterior Biodegradation 102 265-273 (2015).

22. Kouassi Narcisse Aboua, Yao Augustin Yobouet, Kouassi Benjamin Yao, Droh Lancine Gone, Albert Trokourey "Investigation of dye adsorption onto activated carbon from the shells of Macore fruit” J. Environ. Manage 156 10-14 (2015). 
23. Lei Yu, Yong-Ming Luo "The adsorption mechanism of anionic and cationic dyes by Jerusalem artichoke stalk-based mesoporous activated carbon" J Environ Chem Eng 2 220-229 (2014).

24. Hai Nnguyen Tran, Sheng-Jie You, Huan-Ping Chao, "Fast and efficient adsorption of methylene green 5 on activated carbon prepared from new chemical activation method", J. Environ. Manage, 188, 322-336 (2017).

25. Abdelmajid Regti, My Rachid Laamari, Salah-Eddine Stiriba Mohammadine, El Haddad "Potential use of activated carbon derived from Persea species under alkaline conditions for removing cationic dye from wastewaters" J. Assoc. Arab Univ. Basic Appl. Sci (2017)

26. Deepak Pathani, Shikha Sharma, Pardeep Singh, "Removal of methylene blue by adsorption onto activated carbon developed from Ficus carica bast", Arab. J. Chem, 10, S1445-S1451 (2017).

27. F. Asaad Hassan, Hassan Elhadidly, "Production of activated carbons from waste carpets and its applications in methylene blue adsorption: Kinetic and thermodynamic studies”, J. Chem. Eng, 5 (2017), 955-963

28. K.Y. Foo, B.H. Hameed, "Insights into modeling of adsorption isotherm systems", Chem. Eng. J, 156 (2010), 2-10 